\title{
Prevalence and Diversity of MBL Gene-Containing Integrons in Metallo-p-Lactamase (MBL)-Producing Pseudomonas spp. Isolates Disseminated in a Korean Hospital
}

\author{
Jong Hwa Yum ${ }^{\dagger ; *}$ \\ Department of Clinical Laboratory Science, Dongeui University, Busan 47340, Korea
}

\begin{abstract}
Carbapenem is recently considered as the last resort of the therapeutics for gram negative bacterial infection. Increasing of organisms producing metallo- $\beta$-lactamase (MBL), we have difficulty in choosing the antimicrobial agents. Among 345 clinical isolates of Pseudomonas spp., 61 isolates (17.7\%) were positive for the modified imipenem or meropenemHodge test and 55 isolates (15.9\%) were positive for the imipenem-EDTA + SMA double disk synergy test (DDS). PCR and sequencing of bla $a_{\mathrm{VIM}-2}$-allele and bla $_{\mathrm{IMP}-1}$-allele showed that 17 isolates of Pseudomonas aeruginosa, 9 isolates of Pseudomonas taiwnensis and 2 Pseudomonas plecoglossicida had bla $a_{\mathrm{VIM}-2}$, and 22 isolates of P. aeruginosa and one Pseudomonas otitidis had bla $a_{\mathrm{IMP}-6}$. These MBL genes were all in class 1 integron. The size of class 1 integron with $b l a_{\mathrm{VIM}-2}$ ranged from $3.5 \mathrm{~kb}$ to $5.5 \mathrm{~kb}$ in clinical isolates of Pseudomonas spp. including P. aeruginosa. bla $a_{\mathrm{VIM}-2}$ was most often located first in the class 1 integron, sometimes in the second or third position, and these integrons often had aacA4 or aadA1. Strict infection control measures are needed to more effectively prevent further spread of these MBL-producing Pseudomonas spp. In addition, MBL-producing Pseudomonas spp. is expected to continue to spread in various countries and regions.
\end{abstract}

Key Words: Pseudomonas spp., Metallo- $\beta$-lactamase, MBL, $b l a_{\mathrm{VIM}-2,}, b l a_{\mathrm{IMP}-6}$, Carbapenem resistant

\section{서 론}

Pseudomonas spp.는 포도당비발효 그람음성 막대균으로 호흡기계 감염, 요도염 등을 포함한 원내 감염의 중요 원 인균이다(Hong, 2006; Lister et al., 2009; Potron et al., 2015; Farhan et al., 2019). 이들 세균에 의한 위중한 감염 치료에 carbapenems이 주로 널리 사용되었다. 이 항균제는 Pseudomonas spp.의 외막(outer membrane protein)의 portin을 통해 쉽게 침투할 수 있기 때문으로 알려져 있다(Hong et al., 2015). Pseudomonas aeruginosa와 Acinetobacter baumanni의 carbapenem 내성은 최근 흔히 출현하고 있으며, 이 균들
은 주로 원내 감염균으로 분리 빈도가 점차 높아지고 있 고, 흔히 다제 내성을 보인다(Jones et al., 2002; Andrade et al., 2003; Walsh et al., 2005).

Carbapenem에 대한 내성 기전 중 metallo- $\beta$-lactamase (MBL) 생성으로 인한 내성 획득 그람음성 막대균의 출현이 증가하고 있다. Lee 등 (Lee et al., 2003a)에 따르 면 2000 2001년 28개 병원에서 검출된 imipenem 내성 Pseudomonas spp. 387균주 중 44균주와 Acinetobacter spp. 267균주 중 38균주가 MBL 양성이었다. 국내에서 2011년 임상에서 분리된 imipenem 내성 P. aeruginosa는 15,032균 주 중 22\%를 차지한다(Yong et al., 2014). 이들 imipenem 내성 P. aeruginosa는 흔히 다른 계열 약제에도 다제 내성

Received: August 26, 2019 / Revised: October 8, 2019 / Accepted: October 14, 2019

* Professor.

†Corresponding author: Jong Hwa Yum. Department of Clinical Laboratory Science, Dongeui University, Busan 47340, Korea. Tel: +82-51-890-2682, Fax: +82-505-182-6877, e-mail: auxotype@deu.ac.kr

(C) The Korean Society for Biomedical Laboratory Sciences. All rights reserved.

(c) This is an Open Access article distributed under the terms of the Creative Commons Attribution Non-Commercial License (http://creativecommons.org/licenses/by-nc/3.0/) which permits unrestricted non-commercial use, distribution, and reproduction in any medium, provided the original work is properly cited. 
을 보인다.

$\mathrm{MBL}$ 은 분자구조에 따라 5가지 형으로 나뉘며, IMP, VIM, GIM, SIM 및 SPM형이 있다(Lee et al., 2005; Walsh et al., 2005). MBL 중 VIM의 경우 1997년 프랑스에서 분리 된 P. aeruginosa에서 처음 class 1 integron에 위치한 $b l a_{\mathrm{VIM}-2}$ 가 검출되었으며(Poirel et al., 2000), 1995년 국내에서 분 리된 5주의 P. aeruginosa에서도 class 1 integron과 함께 $b l a_{\mathrm{VIM}-2}$ 가 검출되었다(Lee et al., 2002). MBL 유전자 중 하나 인 $b l a_{\mathrm{IMP}-1}$ 은 1988 년 일본에서 처음 보고되었으며(Watanabe et al., 1991), 이들 $\mathrm{MBL}$ 변이종은 점차 증가하고 전파 확 산되고 있다. 또한, 이들 MBL 유전자는 integron에 흔히 있으며, 이들 integron은 이동 가능한 플라스미드에 있어 동종 혹은 이종 간 전파되기 쉽다(Walsh et al., 2005). 이들 $\mathrm{MBL}$ 생성 세균 감염으로 유병율과 사망률이 증가하고 있고(Talbot et al., 2006), 다제 내성인 경우가 많아, 이들 내 성 전파 확산을 관리하지 않으면, $\mathrm{MBL}$ 생성 세균 감염의 치료가 보다 더 어려워질 수 있다. 따라서, 본 연구에서 는 국내 유행하는 MBL 생성 Pseudomonas spp.의 빈도를 조사하고 integron에 위치한 $\mathrm{MBL}$ 형을 규명하고 integron 의 다양성을 분석하고 이들 균들의 항균제 내성 양상을 분석하고자 하였다.

\section{재료 및 방법}

\section{시험 균주의 수집}

국내대학병원 임상검체에서 분리된 Pseudomonas spp. 중 carbapenem 비감수성 균주 345주를 수집하였다. 한 환 자에게서 중복 분리된 균주는 제외하였다. 균종 동정은 전통적인 생화학방법과 상품화된 kit (ID $32 \mathrm{GN}$ system, bioMerieuex, Marcy-l'Etoile, France)를 이용하였다.

\section{분자유전학적 동정}

$16 \mathrm{~S}$ rRNA 유전자 염기서열을 통해 세균을 동정하였는 데, 대상 균주를 부유시킨 멸균수 $100 \mu \mathrm{L}$ 를 $100^{\circ} \mathrm{C}$ 에서 12 분간 중탕 후 $4{ }^{\circ} \mathrm{C}$ 에서 $13,000 \mathrm{rpm}$ 으로 2 분간 원심분리 한 후 상청액 $10 \mu \mathrm{L}$ 를 주형 $\mathrm{DNA}$ 로 사용하여 중합효소연 쇄반응을 시행하였다. 시발체는 5'-AGA GTT TGA TCC TGG CTC AG-3'과 5'-AAG GAG GTG ATC CAG CCG CA-3'를 사용하였으며, Mastercycler gradient (Eppendorf, Hamburg, Germany)를 이용하여 $16 \mathrm{~S} \mathrm{rRNA}$ 유전자를 증폭 시켰다(Löffler et al., 2000). 중합효소연쇄반응 조건은 $94^{\circ} \mathrm{C}$ 5 분 predenaturation 후, $94^{\circ} \mathrm{C} 20$ 초 denaturation, $50^{\circ} \mathrm{C} 40$ 초 annealing, $72^{\circ} \mathrm{C}$ 2분 extension의 과정을 35 회 반복 후 $72^{\circ} \mathrm{C}$ 5 분 extension을 실시하였다. 중합효소연쇄반응 산물은 $0.005 \% \mathrm{EtBr}$ 이 첨가된 $1 \%$ agarose에서 전기영동하여 band 를 확인한 후에 QIAquick Gel Extraction kit (QIAGEN, Hilden, Germany)를 이용하여 증폭된 DNA를 정제하였다. 정제된 DNA는 ABI Prism 3100 Genetic Analyzer (Applied Biosystems, Foster city, CA, USA)를 사용하여 유전자의 염 기서열을 분석하였다.

\section{Carbapenemase 생성 균주의 선별}

Imipenem 혹은 meropenem을 이용한 Hodge 변법 시험 을 시행하고, E. coli ATCC 25922를 지시 세균으로 이용하 였다. E. coli ATCC 25922를 McFarland No. 0.5 탁도관에 맞 추어 MacConkey agar에 멸균된 면봉을 이용하여 고르게 접종한 후, 중앙에 imipenem 혹은 meropenem $10 \mu \mathrm{g}$ disk (Oxoid, Cambridge, UK.)를 놓고 시험 균을 한 줄로 획선 하여 $36^{\circ} \mathrm{C}$ 에서 18 시간 배양하였다. 억제대가 시험 세균 을 따라 증식하면 양성으로 판독하여, carbapenem 내성 Pseudomonase spp. 중 carbapenemase에 의한 내성균을 감 별하여 분리 수집하였다(Lee et al., 2001; Lee et al., 2003b).

\section{$\mathrm{MBL}$ 생성 균주의 선별}

Carbapenem-Hodge 변법 시험에 양성인 균주는 imipenem 혹은 meropenem과 EDTA + sodium mercaptoacetic acid (SMA) double disk synergy 시험(DDS)을 시행하였다 (Lee et al., 2001; Lee et al., 2003b). 시험 균주를 McFarland 0.5 관 탁도로 맞추어 멸균된 면봉을 이용하여 MullerHinton agar에 고르게 접종한 후 imipenem 혹은 meropenem $10 \mu \mathrm{g}$ disk와 $760 \mu \mathrm{g}$ EDTA + $2 \mathrm{mg} \mathrm{SMA} \mathrm{disk를} \mathrm{가장}$ 자리가 $10 \mathrm{~mm}$ 간격으로 놓고 $36^{\circ} \mathrm{C}$ 에서 18 시간 배양하였 다. 두 디스크 사이의 억제대가 커지면 양성으로 판독하 였고, 이들 세균은 $20 \%$ skim milk에 부유하여 $-70^{\circ} \mathrm{C}$ 에 보 관하여 시험에 사용하였다.

\section{$\mathrm{MBL}$ 유전자 분석}

MBL 유전자인 $b l a_{\mathrm{IMP}-1}, b l a_{\mathrm{VIM}-2}, b l a_{\mathrm{AIM}-1}, b l a_{\mathrm{VIM}-1}, b l a_{\mathrm{NDM}-1}$, $b l a_{\mathrm{SIM}-1}$ 유전자를 중합효소 연쇄반응법(PCR)을 이용하여 검출하였다. 각각의 유전자를 검출하기 위한 시발체는 Table 1에 나타내었다. 균주를 멸균수 $100 \mu \mathrm{L}$ 에 부유하여 12 분간 중탕하고 $13,000 \mathrm{rpm}$ 에서 2 분간 원심 후 상청액 을 주형 DNA로 이용하였다. 중합효소연쇄반응 반응은 AccuPower PCR Premix (Bioneer, Daejeon, Korea)에 Tem- 
Table 1. Primers used for detection or sequencing of the MBL genes

\begin{tabular}{cll}
\hline \hline Target & Primer & \multicolumn{1}{c}{ Sequence (5' to 3') } \\
\hline \multirow{2}{*}{$b a_{\mathrm{IMP}-1}$} & IMP1-F & CAT GGT TTG GTG GTT CTT GT \\
& IMP1-R & ATA ATT TGG CGG ACT TTG GC \\
\hline \multirow{2}{*}{$b l a_{\mathrm{VIM}-2}$} & VIM2-FR-F & ATG TTC AAA CTT TTG AGT AAG \\
& VIM2-FR-R & CTA CTC AAC GAC TGA GCG \\
\hline \multirow{2}{*}{$b l a_{\mathrm{AIM}-1}$} & AIM1-F & ATG AAA CGT CGC TTC ACC CTG \\
& AIM1-R & TCA AGG CCG CGC GCC CC \\
\hline \multirow{2}{*}{$b l a_{\mathrm{VIM}-1}$} & VIM1-F & CAC TTC TCG GCG GAG ATT GAA \\
\hline \multirow{2}{*}{$b l a_{\mathrm{NDM}-1}$} & VIM1-R & GTG CTT TGA CAA CGT TCG CT \\
\hline \multirow{2}{*}{$b l a_{\mathrm{SIM}-1}$} & NDM1-F & TCG CAC CGA ATG TCT GGC AGC A \\
& NDM1-R & AAA GCG ATG TCG GTG CCG TCG A \\
\hline
\end{tabular}

plate $1 \mu \mathrm{L}, 20 \mathrm{pmol}$ 의 시발체 $1 \mu \mathrm{L}$, 증류수 $17 \mu \mathrm{L}$ 를 첨가하 여 총 $20 \mu \mathrm{L}$ 으로 시행하였다. Mastercycler Gradient 5331 (Eppendorf, Hamberg, Germany)를 이용하여 $94^{\circ} \mathrm{C} 4$ 분 predenaturation, denaturation $94^{\circ} \mathrm{C} 30$ 초, annealing $55^{\circ} \mathrm{C} 30$ 초, extension $72^{\circ} \mathrm{C} 45$ 초의 조건으로 30 회 반응하고 $72^{\circ} \mathrm{C} 7$ 분 extension하여 반응을 종료하였다. 중합효소연쇄반응 산 물의 확인은 $0.005 \%$ ethium bromide $(\mathrm{EtBr})$ 가 첨가된 $1 \%$ agarose gel을 $100 \mathrm{~V} \mathrm{30}$ 분간 전기영동하고, 중합효소연쇄 반응 산물의 크기 추정을 위하여 $500 \mathrm{bp}$ DNA ladder (TAKARA)를 사용하였다(Lee et al., 2005). 중합효소연쇄 반응 산물은 ABI Prism 3100 Genetic Analyzer (Applied Biosystems, Foster city, CA, USA)를 사용하여 유전자의 염 기서열을 분석하였다.

\section{Integron 유전자 분석}

Class 1 integron은 중합효소연쇄반응법에 의해 검출하였 고, 시발체는 Riccio 등이 제시한 5'CS-F (5'-CTT CTA GAA AAC CGA GGA TGC-3')와 3'CS-R (5'-CTC TCT AGA TTT TAA TGC GGA TG-3')를 사용하였다(Riccio et al., 2000). 중 합효소연쇄반응 조건은 Levesque 등의 방법을 변형하여 시행하였다(Lévesque et al., 1995). 중합효소연쇄반응은 3U LA Taq DNA polymerase (Takara, Shiga, Japan)에 열추출 주형 DNA $5 \mu \mathrm{L}, 20 \mathrm{pmol}$ 의 시발체 $5^{\prime} \mathrm{CS}-\mathrm{F}$ 와 3'CS-R $1 \mu \mathrm{L}$, 최종 $100 \mu \mathrm{L}$ 로 시행하였다. 중합효소연쇄반응은 Mastercycler Gradient 5331 (Eppendorf, Hamberg, Germany)를 이용 하여 predenaturation $94^{\circ} \mathrm{C} 12$ 분, $94^{\circ} \mathrm{C} 1$ 분, $56^{\circ} \mathrm{C} 1$ 분, $72^{\circ} \mathrm{C}$
5 분으로 35 회 시행하였다. 매 회 마다 extension 시간은 5 초씩 증가시켰다. Integrase 유전자, intI1, intI2 및 intI3의 검출은 Shibata 등이 제시한 시발체와 중합효소연쇄반응 조건으로 시행하였다(Shibata et al., 2003).

중합효소연쇄반응 산물은 ABI Prism 3100 Genetic Analyzer (Applied Biosystems, Foster city, CA, USA)를 사용 하여 유전자의 염기서열을 분석하였다.

\section{항균제 감수성 시험}

항균제 감수성 시험은 CLSI (clinical and Laboratory Standards Institute, 2017)의 권고에 따라 $10^{4}$ colony forming units의 접종액을 Mueller-Hinton agar (Difco Laboratories, $\mathrm{USA}$ )에 접종하여 고체한천희석법으로 시행하였다. 시험 에 사용한 항균제는 piperacillin (Wyeth, USA), cephalothin (Sigma Chemical Co., USA), ceftazidime (GlaxoSmithKline, UK), cefotaxime (Handok, Korea), cefoxitin과 imipenem (Merck Sharp \& Dohme, USA), meropenem (Sumitomo, Japan), aztreonam (Bristol-Myers Squibb, USA), amikacin (Dong-A Pharmaceutical, Seoul, Korea), ciprofloxacin (Sigma-Aldrich, China), 그리고 colistin과 polymyxin B (Sigma-Aldrich, St.louis, $\mathrm{Mo}, \mathrm{USA}$ )이었다.

\section{결 과}

Carbapenemase 생성 Pseudomonasspp. 선별 최근 임상에서 분리된 carbapenem 내성 Pseudomonas 
Table 2. Results of Hodge test, double disk synergy test of Pseudomonas spp.

\begin{tabular}{|c|c|c|c|c|c|}
\hline \multirow{2}{*}{ Strains } & \multirow{2}{*}{$\begin{array}{l}\text { No. of } \\
\text { isolates }\end{array}$} & \multicolumn{2}{|c|}{ Hodge test positive strains } & \multicolumn{2}{|c|}{ Double disc synergy test positive strains } \\
\hline & & Imipenem & Meropenem & Imipenem & Meropenem \\
\hline P. aeruginosa & 314 & 45 & 45 & 43 & 15 \\
\hline P. fluorescens & 11 & 2 & 1 & 0 & 0 \\
\hline P. taiwanensis & 9 & 9 & 8 & 9 & 9 \\
\hline P. putida & 8 & 1 & 2 & 0 & 0 \\
\hline P. plecoglossicida & 2 & 2 & 2 & 2 & 1 \\
\hline P. otitidis & 1 & 0 & 1 & 1 & 0 \\
\hline Total & 345 & 59 & 59 & 55 & 25 \\
\hline
\end{tabular}

Table 3. MBL gene types and integron classes of Pseudomonas spp.

\begin{tabular}{|c|c|c|c|c|c|c|c|}
\hline \multirow{3}{*}{ Strains } & \multirow{2}{*}{\multicolumn{2}{|c|}{$\begin{array}{l}\text { Double disk synergy test } \\
\text { positive strains }^{\mathrm{a}}\end{array}$}} & \multicolumn{5}{|c|}{ No. of isolates } \\
\hline & & & \multicolumn{2}{|c|}{ MBL gene type } & \multicolumn{3}{|c|}{ Class of integron } \\
\hline & IMP & MER & $b l a_{\mathrm{VIM}-2}$ & $b l a_{\mathrm{IMP}-6}$ & Int1 & Int 2 & Int3 \\
\hline P. aeruginosa & 43 & 15 & 17 & 22 & 39 & 0 & 0 \\
\hline P. taiwanensis & 9 & 9 & 9 & 0 & 9 & 0 & 0 \\
\hline P. plecoglossicida & 2 & 1 & 2 & 0 & 2 & 0 & 0 \\
\hline P. otitidis & 1 & 0 & 0 & 1 & 1 & 0 & 0 \\
\hline Total & 55 & 25 & 28 & 23 & 51 & 0 & 0 \\
\hline
\end{tabular}

${ }^{\mathrm{a}}$ IMP, imipenem; MER, meropenem

spp. 345주에 대하여 imipenem 혹은 meropenem-Hodge 변 법 시험을 시행한 결과, imipenem에 의해서는 P. aeruginosa가 45주, Pseudomonas fluorescens 2주, Pseudomonas taiwanensis 9주, Pseudomonas putida 1주, Pseudomonas plecoglossicida 2주가 양성을 보였으며, meropenem에 의해 서는 P. aeruginosa 가 45주, P. fluorescens 1 주, P. taiwanensis 8주, P. putida 1주, P. pleccoglossicida 2주, Pseudomonas otitidis 1주가 양성을 보여 총 61주의 carbapenemase 생성 균주를 검출하였고, Hodge 변법 시험에서 imipenem과 meropenem 간에 검출율에 큰 차이는 없었다(Table 2).

\section{Carbapenem-EDTA+SMA double disk synergy 시험}

Imipenem 혹은 meropenem-Hodge 변법 시험에 양성인 균주에 대하여 imipenem 혹은 meropenem-EDTA + SMA double disk synergy 시험 (DDS) 양성인 Pseudomonas spp.는 imipenem에 의해서는 55주, meropenem에 의해서는 25 주 가 $\mathrm{MBL}$ 생성 균주이었다. DDS 시험에 imipenem을 사용 하는 것이 검출율이 2 배 이상 높았다(Table 2).

\section{$\mathrm{MBL}$ 유전자}

Imipenem 혹은 meropenem-EDTA + SMA DDS 양성인 55 주의 $\mathrm{MBL}$ 유전자형을 결정하기 위하여 중합효소연쇄 반응법을 이용하였다. P. aeruginosa 17주, P. taiwanensis 9주 및 P. plecoglossicida 2주에서 bla $\mathrm{VIIM}-2$ allele가 검출되었다 (Table 3). 염기서열 분석으로 이들 균주들은 모두 $b l a_{\mathrm{VIM}-2}$ 임을 확인하였다. 이들 P. aeruginosa 22주와 P. otitidis 1주가 $b l a_{\mathrm{IMP}-1}$ allele가 검출되었다. 염기서열 분석으로 이들 균 주들은 모두 $b l a_{\mathrm{IMP}-6}$ 임을 확인하였다. $b l a_{\mathrm{VIM}-2}$ 와 $b l a_{\mathrm{IMP}-6}$ 외 의 $b l a_{\mathrm{SIM}}, b l a_{\mathrm{AIM}}, b l a_{\mathrm{NDM}}$ 및 $b l a_{\mathrm{VIM}-1}$ allele는 검출되지 않았 다. 이들 51 균주는 모두 class 1 integron이 검출되었고, class 2 integron과 class 3 integron은 검출되지 않았다.

VIM-2 생성 Pseudomonas spp.는 뇨에서 13주, 객담에 서 6주, 창상에서 4주 및 체액에서 5 주가 검출되었고, $P$. aeruginosas는 뇨와 객담에서 각각 6주로 가장 많이 검출 되었고, P. plecoglossicida는 뇨에서 6주로 가장 많이 검출 되었다(Table 4). IMP-6 생성 P. aeruginosa는 뇨에서 20주, 창상에서 2 주가 검출되었고, P. otitidis는 뇨에서 1 주 검출 
Table 4. Source of bla $a_{\mathrm{VIM}-2}$ allele-positive Pseudomonas spp. isolates

\begin{tabular}{|c|c|c|c|c|c|c|}
\hline \multirow{2}{*}{ Source } & \multicolumn{2}{|c|}{ Double disk synergy test positive strains ${ }^{\mathrm{a}}$} & \multicolumn{4}{|c|}{ No. $(\%)$ of isolates ${ }^{b}$} \\
\hline & IMP & MER & PAE & PTA & PPL & Total \\
\hline Urine & 13 & 9 & 6 & 6 & 1 & $13(46)$ \\
\hline Sputum & 6 & 5 & 6 & 0 & 0 & $6(21)$ \\
\hline Wound & 4 & 4 & 4 & 0 & 0 & $4(14)$ \\
\hline Other body fluid & 5 & 4 & 1 & 3 & 1 & $5(17)$ \\
\hline Total & 28 & 22 & $17(61)$ & $9(32)$ & $2(7)$ & $28(100)$ \\
\hline
\end{tabular}

${ }^{\mathrm{a}} \mathrm{IMP}$, imipenem; MER, meropenem

${ }^{\mathrm{b}}$ PAE, P. aeruginosa; PTA, P. taiwanensis; PPL, P. plecoglossicida

Table 5. Source of bla $a_{\mathrm{IMP}-1}$ allele-positive Pseudomonas spp. isolates

\begin{tabular}{|c|c|c|c|c|c|}
\hline \multirow{2}{*}{ Source } & \multicolumn{2}{|c|}{ Double disk synergy test positive strains $\mathrm{s}^{\mathrm{a}}$} & \multicolumn{3}{|c|}{ No. $(\%)$ of isolates ${ }^{b}$} \\
\hline & IMP & MER & PAE & POT & Total \\
\hline Urine & 21 & 3 & 20 & 1 & $21(91)$ \\
\hline Wound & 2 & 0 & 2 & 0 & $2(9)$ \\
\hline Total & 23 & 3 & $22(97)$ & $1(4)$ & $23(100)$ \\
\hline
\end{tabular}

${ }^{\mathrm{a}}$ IMP, imipenem; MER, meropenem

${ }^{\mathrm{b}} \mathrm{PAE}, P$. aeruginosa; POT, $P$. otitidisi

Table 6. Size of class 1 integron, antimicrobial resistance phenotype of bla $a_{\mathrm{VIM}-2}$-positive Pseudomonas spp.

\begin{tabular}{|c|c|c|c|c|}
\hline \multirow{2}{*}{ Strains } & \multirow{2}{*}{ Size $(k b)$ of integron } & \multirow{2}{*}{ No. of isolates } & \multicolumn{2}{|c|}{ Antimicrobial agents susceptibility ${ }^{a}$} \\
\hline & & & Imipenem & Meropenem \\
\hline \multirow{8}{*}{ P. aeruginosa } & \multirow{2}{*}{5.5} & 5 & $\mathrm{R}$ & $\mathrm{R}$ \\
\hline & & 1 & I & $\mathrm{R}$ \\
\hline & 5.0 & 2 & $\mathrm{R}$ & $\mathrm{R}$ \\
\hline & \multirow{2}{*}{4.5} & 6 & $\mathrm{R}$ & $\mathrm{R}$ \\
\hline & & 1 & I & $\mathrm{R}$ \\
\hline & 4.0 & 1 & $\mathrm{R}$ & $\mathrm{R}$ \\
\hline & 3.7 & 1 & $\mathrm{R}$ & $\mathrm{R}$ \\
\hline & 3.5 & 1 & $\mathrm{R}$ & $\mathrm{R}$ \\
\hline \multirow{3}{*}{ P. taiwanensis } & 5.0 & 2 & $\mathrm{R}$ & $\mathrm{R}$ \\
\hline & 4.5 & 1 & $\mathrm{R}$ & $\mathrm{R}$ \\
\hline & 3.5 & 1 & $\mathrm{R}$ & $\mathrm{R}$ \\
\hline \multirow{2}{*}{ P. otitidis } & 5.5 & 1 & $\mathrm{R}$ & $\mathrm{R}$ \\
\hline & 4.5 & 1 & $\mathrm{R}$ & $\mathrm{R}$ \\
\hline
\end{tabular}

${ }^{\mathrm{a}} \mathrm{R}$, resistant; I, Intermediate

되었다(Table 5). 또한, IMP-6 생성 균주는 imipenem-EDTA

+ SMA DDS 시험에서 23주가 양성이었고, meropenem$\mathrm{EDTA}+\mathrm{SMA} \mathrm{DDS}$ 시험에서 3주가 양성으로 나타나 MBL 검출을 위한 DDS 시험에 meropenem보다는 imipenem을
이용하는 것이 효율적이었다.

$\mathrm{MBL}$ 생성 균의 integron

$\mathrm{MBL}$ 생성 P. aeruginosa 중 $5.5 \mathrm{~kb}, 5.0 \mathrm{~kb}, 4.5 \mathrm{~kb}, 4.0 \mathrm{~kb}$, 
Table 7. Antimicrobial agent susceptibility for $b l a_{\mathrm{VIM}-2}$-positive Pseudomonas spp. with different the position of $b l a_{\mathrm{VIM}-2}$ cassette in class 1 integrons

\begin{tabular}{|c|c|c|c|c|}
\hline \multirow{2}{*}{ Strains } & \multirow{2}{*}{$\begin{array}{l}\text { Position of } b l a_{\mathrm{VIM}-2} \\
\quad \text { cassette }\end{array}$} & \multirow{2}{*}{ No. of strains } & \multicolumn{2}{|c|}{ Antimicrobial agents susceptibility ${ }^{\mathrm{a}}$} \\
\hline & & & Imipenem & Meropenem \\
\hline \multirow{3}{*}{ P. aeruginosa } & Frst & 6 & $\mathrm{R}$ & $\mathrm{R}$ \\
\hline & Second & 1 & $\mathrm{R}$ & $\mathrm{R}$ \\
\hline & Third & 1 & $\mathrm{R}$ & $\mathrm{R}$ \\
\hline \multirow{2}{*}{ P. taiwanensis } & First & 2 & $\mathrm{R}$ & $\mathrm{R}$ \\
\hline & Second & 2 & $\mathrm{R}$ & $\mathrm{R}$ \\
\hline P. plecoglossicida & Second & 1 & $\mathrm{R}$ & $\mathrm{R}$ \\
\hline
\end{tabular}

${ }^{\mathrm{a}} \mathrm{R}$, resistant

Table 8. MICs of antimicrobial agents for MBL-producing clinical isolates of Pseudomonas spp. in Korean hospital

\begin{tabular}{|c|c|c|c|c|c|c|c|c|c|c|c|c|c|}
\hline \multirow{2}{*}{$\begin{array}{l}\text { MBL } \\
\text { types }\end{array}$} & \multirow{2}{*}{$\begin{array}{c}\text { Strains } \\
\text { (No. of } \\
\text { isolates) }^{\mathrm{b}}\end{array}$} & \multicolumn{12}{|c|}{ MIC range $(\mu \mathrm{g} / \mathrm{mL})^{\mathrm{a}}$} \\
\hline & & IPM & MEM & AZT & CTX & CAZ & CEP & FOX & PIP & AMK & CIP & $\mathrm{COL}$ & POLY B \\
\hline \multirow{3}{*}{ VIM-2 } & $\operatorname{PAE}(17)$ & $16 \sim 128$ & $2 \sim 64$ & $4 \sim 128$ & $>128$ & $16 \sim>128$ & $>128$ & $>128$ & $16 \sim>256$ & $4 \sim>128$ & $0.25 \sim>128$ & $0.25 \sim 4$ & $0.12 \sim 2$ \\
\hline & PTA (9) & $16 \sim 128$ & $16 \sim>128$ & $64 \sim 128$ & $128 \sim>128$ & $32 \sim 128$ & $>128$ & $>128$ & $64 \sim>256$ & $4 \sim>128$ & $>128$ & 0.5 & $0.5 \sim 1$ \\
\hline & PPL (2) & $64 \sim 128$ & $64 \sim 128$ & 128 & $>128$ & 64 & $>128$ & $>128$ & $64 \sim 128$ & $4 \sim 128$ & $>128$ & 0.5 & 0.5 \\
\hline \multirow{2}{*}{ IMP-6 } & $\operatorname{PAE}(22)$ & $8 \sim 32$ & $>128$ & $4 \sim 64$ & $>128$ & $64 \sim>128$ & $>128$ & $>128$ & $32 \sim 256$ & $128 \sim>128$ & $16 \sim 32$ & $0.25 \sim 0.5$ & $0.5 \sim 1$ \\
\hline & POT (1) & 8 & $>128$ & 16 & $>128$ & 64 & $>128$ & $>128$ & 128 & 128 & 16 & 0.5 & 0.5 \\
\hline
\end{tabular}

${ }^{a}$ IMP, imipenem; MEM, meropenem; AZT, aztreonam; CTX, cefotaxime; CAZ, ceftazidime; CEP, cephalothin; FOX, cefoxitin; PIP, piperacillin; AMK, amikacin; CIP, ciprofloxacin; COL, colistin; POLY B, polymyxin B.

${ }^{\mathrm{b}}$ PAE, P. aeruginosa; PTA, P. taiwanensis; PPL, P. plecoglossicida; POT, P. otitidis

$3.7 \mathrm{~kb}, 3.5 \mathrm{~kb}$ 의 class 1 integron을 각각 6주, 2주, 7주, 1 주, 1 주 및 1 주가 가지고 있었다(Table 6). MBL 생성 P. taiwanensis 중 $5.0 \mathrm{~kb}, 4.5 \mathrm{~kb}, 3.5 \mathrm{~kb}$ 의 class 1 integron을 각각 2주, 1 주 및 1 주가 가지고 있었다. MBL 생성 P. otitidis 중에는 $5.5 \mathrm{~kb}$ 와 $4.5 \mathrm{~kb}$ 의 class 1 integron을 각각 2주가 가지고 있

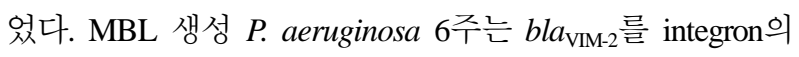
첫 번째 카세트 위치에 있었고, 2 주는 각각 두 번째 카세 트와 세 번째 카세트 위치에 있었다(Table 7). MBL 생성 $P$. taiwanensis 2 주는 $b l a_{\mathrm{VIM}-2}$ 를 integron의 첫 번째 카세트 위 치에 있었고, 다른 2 주는 두 번째 카세트에 있었다. MBL 생성 P. plecoglossicida 1 주는 bla $a_{\mathrm{VIM}-2}$ 를 두 번째 카세트에 있었다. MBL 생성 Pseudomonas spp.의 bla $a_{\mathrm{VIM}-2}$ 유전자 카 세트는 주로 class 1 integron의 5'에 가까운 위치에 있었고, 이들 균주는 모두 imipenem과 meropenem에 내성이었다.

\section{$\mathrm{MBL}$ 생성 Pseudomonas spp.에 대한 항균제 감수성}

VIM-2 생성 P. aeruginosa에 대한 imipenem과 meropenem의 $\mathrm{MIC}$ 는 각각 $16 \sim 128 \mu \mathrm{g} / \mathrm{mL}$ 와 2 64 $\mu \mathrm{g} / \mathrm{mL}$ 이었
고, cefotaxin, ceftazidime 및 cefoxitin의 $\mathrm{MIC}$ 는 각각 $>128$ $\mu \mathrm{g} / \mathrm{mL}, 16 \sim 128 \mu \mathrm{g} / \mathrm{mL}$, 그리고 > $128 \mu \mathrm{g} / \mathrm{mL}$ 이었고, 대부 분의 $\beta$-lactam 제제에 높은 MIC 값을 보였다(Table 8). Aztreonam의 MIC는 4 128 $\mu \mathrm{g} / \mathrm{mL}$ 로 감수성을 보이는 균 주도 있었다. Amikacin의 MIC는 4 > $128 \mu \mathrm{g} / \mathrm{mL}$ 이었고, colistin과 polymyxin B의 $\mathrm{MIC}$ 는 각각 $0.25 \sim 4 \mu \mathrm{g} / \mathrm{mL}$ 와 $0.12 \sim 2 \mu \mathrm{g} / \mathrm{mL}$ 으로 비교적 낮은 값을 나타냈다. VIM-2 생 성 P. taiwanensis와 P. plecoglossicida는 P. aeruginosa와 유 사한 결과를 보였으나, Aztreonam의 MIC는 64 128 $\mu \mathrm{g} /$ $\mathrm{mL}$ 로 감수성인 균주는 없었고, colistin과 polymyxin $\mathrm{B}$ 의 $\mathrm{MIC}$ 는 각각 $0.5 \mu \mathrm{g} / \mathrm{mL}$ 와 $0.5 \sim 1 \mu \mathrm{g} / \mathrm{mL}$ 로 모두 감수성이 었다.

IMP-6 생성 Pseudomonas spp.에 대한 imipenem과 meropenem의 MIC는 각각 $8 \sim 32 \mu \mathrm{g} / \mathrm{mL}$ 과 > $128 \mu \mathrm{g} / \mathrm{mL}$ 로 meropenem의 MIC 값이 비교적 높았다(Table 8). 이들 균주에 대한 cefotaxin, ceftazidime, cefoxitin 및 aztreonam의 MIC 는 각각 >128 $\mu \mathrm{g} / \mathrm{mL}, 64 \sim 128 \mu \mathrm{g} / \mathrm{mL},>128 \mu \mathrm{g} / \mathrm{mL}$ 및 4 $64 \mu \mathrm{g} / \mathrm{mL}$ 이었다. Amikacin의 MIC는 $128 \sim 128 \mu \mathrm{g} / \mathrm{mL}$ 으 
로 IMP-6 생성 Pseudomonas spp.는 모두 높은 MIC 값으 로 내성을 보였다. Colistin과 polymyxin $\mathrm{B}$ 의 $\mathrm{MIC}$ 는 각각 $0.25 \sim 0.5 \mu \mathrm{g} / \mathrm{mL}$ 와 $0.5 \sim 1 \mu \mathrm{g} / \mathrm{mL}$ 이었고, 이들 IMP-6 생성 Pseudomonas spp. 모두 감수성이었다.

\section{고 찰}

많은 나라에서 $\mathrm{MBL}$ 생성 그람음성 막대균이 증가하고 있어(Arakawa et al., 2000; Lee et al., 2001) 일선 검사실에서 $\mathrm{MBL}$ 생성 균주의 검출에 효율적이 검사 방법이 필요하다. 흔히 MBL 생성 균주 선별에 cabapenem-Hodge 변법 시 험과 DDS 시험을 사용하는데(Lee et al., 2001; Lee et al., 2003b), 이 시험에 항균제 디스크로 imipenem을 흔히 사 용한다. 한편, 일본의 Arakawa 등 (Arakawa et al., 2000)은 $\mathrm{MBL}$ 생성 균주 선별에 DDS 시험에 caftazidime을 이용하 는 것이 유리하다고 보고한 바 있다. 본 연구에서 $\mathrm{MBL}$ 생성 Pseudomonas spp. 선별에 imipenem과 meropenem 을 사용하여 Hodge 변법 시험을 시행하였을 때, 두 항균 제 디스크 간 결과에 큰 차이는 없었다. 그러나, DDS 시 험에서는 imipenem을 사용했을 때 보다 meropenem의 경 우 검출율이 $50 \%$ 정도 낮았다(Table 2, 3). MBL 생성 Pseudomonas spp. 선별에 DDS 시험 시 meropenem 보다 는 imipenem을 사용하는 것이 효율적으로 판단된다. $\mathrm{MBL}$ 생성 Pseudomonas spp. 중에는 imipenem보다 meropenem 의 $\mathrm{MIC}$ 가 낮은 균주들이 있어, DDS 시험 시 meropenem 디스크를 이용한 DDS 시험에서 위음성 결과를 보이는 균 주가 있는 것으로 보인다.

2004년도 전국 대학병원 중환자실 병원감염 감시 결과 (Kim et al., 2004)에 따르면 부위별 감염분포 결과는 요로 감염(36.8\%), 폐렴(35.2\%), 균혈증(14.9\%) 순으로 나타났는 데, 본 연구에서도 $\mathrm{MBL}$ 생성 Pseudomonas spp.의 검체 별 분리율이 뇨에서 가장 높아 유사한 결과를 보였다 (Table 4, 5).

국내 병원에서 imipenem 내성 P. aeruginosa는 1997년 $16 \%$ 로 이미 높은 분리율을 보였고, 계속적으로 높은 분 리율을 보였다. 이들 내성 균주의 $9 \%$ 정도는 $\mathrm{MBL}$ 생성 균주이었고, 이들 모두는 $b l a_{\mathrm{VIM}-2}$ 를 가지고 있었다(Lee et al., 2002). Imipenem에 내성인 MBL 생성 Psedomonas spp. 는 폴란드, 그리스, 이태리 및 일본 등 지역이나 국가에 따른 분자생물학적 역학을 보고하였다(Giakkoupi et al., 2003; Kimura et al., 2005; Riccio et al., 2005; Toleman et al., 2005; Fiett et al., 2006). 유럽에서는 VIM형 MBL이 주로
검출되고, 가까운 일본에서는 IMP-1이 주로 검출되었으나, 국내에서는 1995 년 $b l a_{\mathrm{VIM}-2}$ 형 MBL이 한 동안 계속 검출 되었다(Lauretti et al., 1999; Poirel et al., 2000; Lee et al., 2002; Yang et al., 2012).

일본(Yano et al., 2001)에서 발견된 IMP-6 type이 국내에 서도 출현하고 있다. IMP-6 type은 IMP-1과 비교하여 하 나의 아미노산 서열만이 바뀌어(Ser196Gly) meropenem에 대한 활성이 증가하고 penicillin에 대한 활성은 감소되었 다(Yano et al., 2001). 2009년, 국내에서 검출된 MBL 생성 P. aeruginosa는 IMP-6 생성 균이 많이 퍼진 것으로 보고 하였다(Seok et al., 2011). 본 연구에서는 MBL 생성 $P$. aeruginosa, P. taiwanensis 및 P. plecoglossicida에서 각각 17 주, 9주 및 2주에서 $b l a_{\mathrm{VIM}-2}$ 가 검출되었고, P. aeruginosa 와 P. otitidis에서 각각 22주와 2주에서 $b l a_{\mathrm{IMP}-6}$ 검출되어 국내 MBL 생성 Pseudomonas spp.는 $b l a_{\mathrm{VIM}-2}$ 와 $b l a_{\mathrm{IMP}-6}$ 가 주로 전파되고 있고, P. aeruginosa 간에는 $b l a_{\mathrm{VIM}-2}$ 보다 $b l a_{\mathrm{IMP}-6}$ 가 더 만연하고 있고, 검출된 $\mathrm{MBL}$ 생성 Pseudomonas spp. 중에는 아직 $b l a_{\mathrm{VIM}-2}$ 가 더 많이 전파되고 있 었다.

2003년, 국내 MBL 생성 그람음성 막대균 중 최초로 $b l a_{\mathrm{SIM}}$ 을 가지는 Acinetobacter baumannii가 검출되었는데, class 1 integron에 위치하였다(Lee et al., 2005). 항균제 내성 유전자가 integron에 카세트 구조로 있을 경우, 내성 유전 자가 프라스미드의 전파, 트랜스포손 자신과 내부 유전자 이동 및 integron 간 카세트 이동 기전으로 세균 간에 내 성 유전자의 이동이 용이할 수 있는데, 본 연구에서 $\mathrm{MBL}$ 생성 Pseudomonas spp.에서 bla $a_{\mathrm{SIM}}$ 유전자는 검출되지 않 았다(Table $3,4,5)$. 이는 항균제 내성 유전자가 integron에 위치할 때, 이동 전파가 용이할 수 있지만, imipenem이나 meropenem과 같은 carbapenem의 사용이 많아지면, 세균은 해당 항균제에 대한 내성 유전자를 가지고 있으려는 경 향 때문에 항균제 가수분해능이 높은 항균제 내성 유전 자를 선호하는 것으로 보인다. 또한, Lee 등의 보고에 의 하면 $b l a_{\mathrm{SIM}}$ 을 가지는 Acinetobacter baumanni의 imipenem과 meropenem의 $\mathrm{MIC}$ 는 $8 \sim 16 \mu \mathrm{g} / \mathrm{mL}$ 과 $16 \mu \mathrm{g} / \mathrm{mL}$ 으로 비교적 낮다. 항균제에 대해 내성을 보이는 기전은 efflux pump 등과 같은 기전도 영향을 미치지만, 이들 결과는 아마도 SIM 효소의 imipenem과 meropenem의 가수분해능이 VIM 이나 IMP보다 낮은 이유 때문인 것으로 보인다.

$b l a_{\mathrm{VIM}-2}$ 는 흔히 integron에 위치하는데, $b l a_{\mathrm{VIM}-2}$ 가 위치 한 integron의 크기와 카세트 배열은 다양하게 보고되었 다(Lauretti et al., 1999; Poirel et al., 2000; Lee et al., 2002; 
Quinteria et al., 2005; Lolans et al., 2005; Kim et al., 2005). 캐나다에서 출현한 $b l a_{\mathrm{VIM}-2}$ 를 갖는 integron은 $a a c C l$ 과 $a a c A 4$ 를 함께 가지고 있었고(Pitout et al., 2007), 미국에서 출현한 $b l a_{\mathrm{VIM}-2}$ 를 갖는 integron은 $b l a_{\mathrm{VIM}-2}$ 는 두 번째 카세 트에 위치하고, $a a c A 7, d h f r$ 및 $a a c C-A 5$ 를 함께 가지고 있 었다(Lolans et al., 2005). 국내에서 2002년, Lee 등이 보고 한 MBL 생성 P. aeruginosa에서 두 번째 카세트에 위치 한 $b l a_{\mathrm{VIM}-2}$ 를 갖는 integron은 aacA4, orfI, ofrII 및 $a a d A l$ 를 갖고 있었다(Lee et al., 2002). 본 연구에서는 $b l a_{\mathrm{VIM}-2}$ 혹은 $b l a_{\mathrm{IMP}-6}$ 를 갖는 integron은 $a a c A 4$ 와 $a a d A l$ 을 갖고 있었다 (data not shown)고, P. aeruginosa, P. taiwanensis 및 P. otitidis 는 $3.5 \sim 5.5 \mathrm{~kb}, 3.5 \mathrm{~kb}$ 및 $4.5 \sim 5.5 \mathrm{~kb}$ 의 $b l a_{\mathrm{VIM}-2}$ 를 갖는 integron이 검출되었으며, Pseudomonas spp. 한 균주가 1 개 에서 3 개의 integron을 흔히 가지고 있었다. 이는 시기와 지역에 따라 Pseudomonas spp.가 다양한 내성 유전자를 갖는 integron을 가지고 있었다. 또한, 흔히 사용하는 항균 제 압력에 따라 항균제 내성을 보이는 균주가 필요한 내 성 유전자를 소유하면서 가지고 있는 내성 유전자가 계 속적으로 변화하는 것으로 판단된다.

Integron의 내성 유전자의 발현은 integron의 5' 방향의 promoter에 영향을 받는데, promoter의 종류에 따른 발현 정도에 차이도 있지만, 내성 유전자 카세트의 위치에 따 라 promoter와 가까울수록 강하게 발현되는 것으로 알려 져 있다(Levesque et al., 1995). 본 연구에서 MBL 생성 Pseudomonas spp.의 integron은 $b l a_{\mathrm{VIM}-2}$ 의 첫 번째 카세트 위치에 있는 균주는 8균주, 두 번째 카세트 위치에 있는 균주는 4균주, 그리고 세 번째 카세트 위치에 있는 균주 는 1균주로 나타났다(Table 7). 이는 위중한 MBL 생성 균 주 감염 시 carbapenem의 사용이 증가함에 따라 보다 효 율적으로 $\mathrm{MBL}$ 유전자를 발현하기 위해 첫 번째 유전자 카세트에 위치하는 경우가 많은 것으로 보인다. 그러나, 본 연구에서 imipenem과 meropenem의 MIC 값이 크게 차 이가 없었다(Table 8). 이는 항균제 내성 기전은 효소에 의 한 것도 있지만, efflux pump 발현이나 $\mathrm{AmpC}$ 유전자 발현 등의 차이에 의해서 표현형에 차이를 나타내지 못할 수 있는 것 판단된다. VIM-2 생성 Pseudomonas spp.와 IMP-6 생성 Pseudomonas spp.에 대한 imipenem의 $\mathrm{MIC}$ 는 각각 $16 \sim 128 \mu \mathrm{g} / \mathrm{mL}$ 과 $8 \sim 32 \mu \mathrm{g} / \mathrm{mL}$ 이었고, meropenem의 $\mathrm{MIC}$ 는 2 64 $\mu \mathrm{g} / \mathrm{mL}$ 과 $>128 \mu \mathrm{g} / \mathrm{mL}$ 로 비교적 높은 값을 보이 며, 대부분의 균주가 내성이었고, 대부분의 $\beta$-lactam 제제 의 $\mathrm{MIC}$ 가 높고 ciprofoxacin과 같은 다른 계열 항균제의 MIC도 높은 균주도 많았다(Table 8). 이에 반해 colistin과 polymyxin $\mathrm{B}$ 의 $\mathrm{MIC}$ 는 낮아 대부분 균주가 감수성이었다. 그러나, colistin과 polymyxin $\mathrm{B}$ 의 사용이 증가한다면, 이들 항균제에 대한 내성도 증가할 것으로 예상되므로, 그람 음성 막대균에 대한 새로운 항균제의 개발이 필요해 보 인다.

MBL 생성 Pseudomonas spp.는 국내 대학병원에서 높은 출현율을 보이고 있다. VIM-2 생성 Pseudomonas spp.는 과거와 비슷한 정도의 출현율이 유지되고 있으며, IMP-6 생성 Pseudomonas spp. 점진적으로 증가하고 있는 추세 이다. 이들 $\mathrm{MBL}$ 생성 균주의 추가 확산을 보다 더 효과 적으로 예방하기 위한 엄격한 감염 관리 조치가 필요하 다. 또한, 다양한 나라와 지역의 의료기관에서 $\mathrm{MBL}$ 생성 Pseudomonas spp.는 계속적인 전파 확산이 예견되므로, 계 속적인 분자생물학적 조사 등이 필요할 것으로 판단된다.

\section{ACKNOWLEDGEMENT}

균주 수집에 도움을 주신 신촌세브란스병원의 이혁민 교수님께 감사드립니다.

\section{CONFLICT OF INTEREST}

The author declares no conflict of interest.

\section{REFERENCES}

Andrade SS, Jones RN, Gales AC, Sader HS. Increasing prevalence of antimicrobial resistance among Pseudomonas aeruginosa isolates in Latin American medical centres: 5 year report of the SENTRY Antimicrobial Surveillance Program (19972001). J Antimicrob Chemother. 2003. 52: 140-141.

Arakawa Y, Shibata N, Shibayama K, Kurokawa H, Yagi T, Fujiwara H, Goto M, Convenient test for screening metallo$\beta$-lactamase-producing Gram-negative bacteria by using thiol compounds. J Clin Microbiol. 2000. 38: 40-43.

Clinical and Laboratory Standards Institute. Performance standards for antimicrobial susceptibility tests; approved standards M2-A8, 27th ed. Wayne PA: CLSI; 2017.

Farhan SM, Ibrahim RA, Mahran KM, Hetta HF, Abd ERM. Antimicrobial resistance pattern and molecular genetic distribution of metallo- $\beta$-lactamases producing Pseudomonas aeruginosa isolated from hospitals in Minia, Egypt. Infect Drug Resist. 2019. 12: 2125-2133.

Fiett J, Baraniak A, Mrowka A, Fleischer M, Drulis-Kawa Z, Naumiuk L, Samet A, Hryniewicz W, Gniadkowski M. 
Molecular epidemiology of acquired-metallo-beta-lactamaseproducing bacteria in Poland. Antimicrob Agents Chemother. 2006. 50: $880-886$.

Giakkoupi P, Petrikkos G, Tzouvelekis LS, Tsonas S, Legakis NJ, Vatopoulos AC. Spread of integron-associated VIM-type metallo-beta-lactamase genes among imipenem-nonsusceptible Pseudomonas aeruginosa strains in Greek hospitals. J Clin Microbiol. 2003. 41: 822-825.

Hong JS, Kim JO, Lee H, Bae IK, Jeong SH, Lee K. Characteristics of Metallo- $\beta$-Lactamase-producing Pseudomonas aeruginosa in Korea. Infect Chemother. 2015. 47: 33-40.

Hong S-B. In vitro Antimicrobial Combination Therapy in Metallo$\beta$-lactamase Producing Pseudomonas aeruginosa. Korean Journal of Clinical Laboratory Science. 2006. 38: 166-172.

Jones RN, Kirby JT, Beach ML, Biedenbach DJ, Pfaller MA. Geographic variations in activity of broad-spectrum $\beta$-lactams against Pseudomonas aeruginosa: summary of the worldwide SENTRY Antimcrobial Surveillance Program (1997-2000). Diagn Microbiol Infect Dis. 2002. 43: 239-243.

Kim I-S, Lee NY, Ki C-S, Oh WS, Peck KR, Song J-H. Increasing prevalence of imipenem-resistant Pseudomonas aeruginosa and molecular typing of metallo-beta-lactamase producers in a Korean Hospital. Microb Drug Resistance. 2005. 11: 3355 -3558 .

Kim IS, Oh WI, Song JH, Lee NY. Screening and Identification of Metallo- $\beta$-Lactamase Gene in Clinical Isolates of ImipenemResistant Pseudomonas aeruginosa. Korean J Lab Med. 2004. 24: 177-182.

Kimura S, Alba J, Shiroto K, Sano R, Niki Y, Maesaki S, Akizawa K, Kaku M, Watanuki Y, Ishii Y, Yamaguchi K. Clonal diversity of metallo-beta-lactamase-possessing Pseudomonas aeruginosa in geographically diverse regions of Japan. J Clin Microbiol. 2005. 43: 458-461.

Lauretti L, Riccio ML, Mazzariol A, Cornaglia G, Amicosante G, Fontana R, Rossolini GM. Cloning and characterization of $b l a_{\mathrm{VIM}}$, a new integron-borne metallo-beta-lactamase gene from a Pseudomonas aeruginosa clinical isolate. Antimicrob Agents Chemother. 1999. 43: 1584-1590.

Lee K, Chong Y, Shin HB, Kim YA, Yong D, Yum JH. Modified Hodge test and EDTA-disk synergy tests to screen metallo- $\beta$ lactamase-producing strains of Pseudomonas and Acinetobacter species. Clin Microbiol Infect. 2001. 7: 88-91.

Lee K, Lee WG, Uh Y, Ha GY, Cho J, Chong Y. Korean Nationwide Surveillance of Antimicrobial Resistance Group. VIM- and IMP-type metallo-beta-lactamase-producing Pseudomonas spp. and Acinetobacter spp. in Korean hospitals. Emerg Infect Dis. 2003a. 9: 868-871.

Lee K, Lim JB, Yum JH, Yong D, Chong Y, Kim JM, Livermore DM. $b l a_{\mathrm{VIM}-2}$ cassette-containing novel integrons in metallo$\beta$-lactamase-producing Pseudomonas aeruginosa and Pseudomonas putida isolates disseminated in ad Korean hospital. Antimicrob Agents Chemother. 2002. 46: 1053-1058.

Lee K, Lim YS, Yong D, Yum JH, Chong Y. Evaluation of the Hodge Test and the imipenem-EDTA double disk synergy test for differentiating metallo-beta-lactamase-producing clinical isolates of Pseudomonas spp. and Acinetobacter spp. J Clin Microbiol. 2003b. 41: 4623-4629.

Lee K, Yum JH, Yong D, Lee HM, Kim HD, Docquier JD, Rossolini GM, Chong Y. Novel acquired metallo- $\beta$-lactamase gene, $b l a_{\mathrm{SIM}-1}$, in a class 1 integron from Acinetobacter baumannii clinical isolates from Korea. Antimicrob Agents Chemother. 2005. 49: 4485-4491.

Lévesque C, Piché L, Chantal L, Roy PH. PCR mapping of integrons reveals several novel combinations of resistance genes. Antimicrob Agents Chemother. 1995. 39: 185-191.

Lister PD, Wolter DJ, Hanson ND. Antibacterial-resistant Pseudomonas aeruginosa: clinical impact and complex regulation of chromosomally encoded resistance mechanisms. Clin Microbiol Rev. 2009. 22: 582-610.

Löffler FE, Sun Q, Li J, Tiedje JM. 16S rRNA gene-based detection of tetrachloroethene-dechlorinating Desulfuromonas and Dehalococcoides species. Appl Environ Microbiol. 2000. 66: 1369-1374.

Lolans K, Queenan AM, Bush K, Sahud A, Quinn JP. First Nosocomial outbreak of Pseudomonas aeruginosa producing an integron-borne metallo-beta-lactamase (VIM-2) in the United States. Antimicrob Agents Chemother. 2005. 49: 3538-3540.

Pitout JDD, Chow BL, Gregson DB, Laupland KB, Elsayed S, Chrch DL. Molecular Epidemiology of Metallo-beta-Lactamase -Producing Pseudomonas aeruginosa in the Calgary Health Region: Emergence of VIM-2-Producing Isolates. J Clin Microbiol. 2007. 43: 458-461.

Poirel L, Naas T, Nicolas D, Collet L, Bellais S, Cavallo J-D, Nordmann P. Characterization of VIM-2, a carbapenemhydrolyzing metallo-beta-lactamase and its plasmid- and integron-borne gene from a Pseudomonas aeruginosa clinical isolate in France. Antimicrob Agents Chemother. 2000. 44: 891-897.

Potron A, Poirel L, Nordmann P. Emerging broad-spectrum resistance in Pseudomonas aeruginosa and Acinetobacter bau- 
mannii: mechanisms and epidemiology. Int $\mathrm{J}$ Antimicrob Agents. 2015. 45: 568-585.

Quinteira S, Souse JC, Peixe L. Characterization of In100, a New integron carrying a metallo- $\beta$-lactamase and a carbenicillinase, from Pseudomonas aeruginosa. Antimicrob Agents Chemother. 2005. 49: 451-453.

Riccio ML, Franceschini N, Boschi L, Caravelli B, Cornaglia G, Fontana R, Amicosante G, Rossolini GM. Characterization of the metallo-beta-lactamase determinant of Acinetobacter baumannii AC-54/97 reveals the existence of bla(IMP) allelic variants carried by gene cassettes of different phylogeny. Antimicrob Agents Chemother. 2000. 44: 1229-1235.

Riccio ML, Pallecchi L, Docquier JD, Cresti S, Catania MR, Pagani L, Lagatolla C, Cornaglia G, Fontana R, Rossolini GM. Clonal relatedness and conserved integron structures in epidemiologically unrelated Pseudomonas aeruginosa strains producing the VIM-1 metallo-beta-lactamase from different Italian hospitals. Antimicrob Agents Chemother. 2005. 49: 104-110.

Seok Y, Bae IK, Jeong SH, Kim SH, Lee H, Lee K. Dissemination of IMP-6 metallo- $\beta$-lactamses-producing Pseudomonas aeruginosa sequence type 235 in Korea. J Antimicrob Chemother. 2011. 66: 2791-2796

Shibata N, Doi Y, Yamane K, Yagi T, Kurokawa H, Shibayama K, Kato H, Kai K, Arakawa Y. PCR Typing of Genetic determinants for metallo-beta-lactamases and integrases carried by gram-negative bacteria isolated in Japan, with focus on the class 3 integron. J Clin Microbiol. 2003. 43: 458-461.

Talbot GH, Bradley J, Edwards JE, Gilbert D, Scheld M, Bartlett JG. Bad bugs need drugs: an update on the development pipeline from the Antimicrobial Availability Task Force of the Infectious Diseases Society of America. Clin Infect Dis. 2006. 42: 657-668.
Toleman MA, Biedenbach D, Bennett DM, Jones RN, Walsh TR. Italian metallo-beta-lactamases: a national problem? Report from the SENTRY Antimicrobial Surveillance Programme. J Antimicrob Chemother. 2005. 55: 61-70.

Walsh TR, Toleman MA, Poirel L, Nordmann P. Metallo-betalactamases: the quiet before the storm? Clin Microbiol Rev. 2005. 18: 306-325.

Watanabe JJ, Ko WC, Wu JJ. Transferable imipenem resistance in Pseudomonas aeruginosa. Antimicrob Agents Chemother. 1991. 45: 1343-1348.

Yang B-S, Hong K-S, Jung S-B, Kwon Y-H, Jeong JY, Lee M-J, Lee H-I, Park M-S, Choi S-G. Phenotypic and Genotypic Detection of Metallo- $\beta$-Lactamase Producing Pseudomonas aeruginosa. Korean Journal of Clinical Laboratory Science. 2012. 44: 81-85.

Yano H, Kuga A, Okamoto R, Kitasato H, Kobayashi T, Inoue M. Plasmid-encoded metallo- $\beta$-lactamase (IMP-6) conferring resistance to carbapenems, especially meropenem. Antimicrob Agents Chemother. 2001. 45: 1343-1348.

Yong D, Shin HB, Kim YK, Cho J, Lee WG, Ha GY, et al. Increase in the prevalence of carbapenem-resistant Acinetobacter isolates and ampicillin-resistant non-typhoidal Salmonella species in Korea: a KONSAR study conducted in 2011. Infect Chemother. 2014. 46: 84-93.

https://doi.org/10.15616/BSL.2019.25.4.321

Cite this article as: Yum JH. Prevalence and Diversity of MBL Gene-Containing Integrons in Metallo- $\beta$ Lactamase (MBL)-Producing Pseudomonas spp. Isolates Disseminated in a Korean Hospital. Biomedical Science Letters. 2019. 25: 321-330. 